\title{
Individual neuropsychological characteristics in patients with juvenile myoclonic epilepsy
}

\author{
Polina V. Moskaleva ${ }^{a^{*}}$, Olga S. Shilkina ${ }^{a}$, Natalia A. Shnayder ${ }^{a, b}$ \\ a Krasnoyarsk State Medical University, Krasnoyarsk, Russia \\ ${ }^{\mathrm{b}}$ National Medical Research Centre of Psychiatry and Neurology, Saint-Petersburg, Russia \\ ${ }^{*}$ Corresponding author: E-mail: Polina-Moscaleva@yandex.ru
}

Background. An association between juvenile myoclonic epilepsy (JME) and nonpsychotic psychiatric and cognitive disorders has been described in recent years. Scientists are trying to link JME with certain personality traits marked by emotional instability.

Objective. The goal of our research was to assess the state of cognitive functions in young adult patients with JME-excluding the adverse side effects (ASEs) of antiepileptic drugs (AEDs)-and analyze the level of personality and situational anxiety, neuroticism, and depression in young adult patients with JME.

Design. We tested 26 patients with JME and 26 healthy adults with the computer program NS-PsychoTest (Neurosoft Company, RF), a program which is aimed at studying and evaluating neuropsychological characteristics.

Results. Our study showed that the frequency of depressive symptoms, according to the cognitive-affective subscale (Beck's Depression Inventory), in patients with JME was statistically significantly higher than among people without epilepsy. Comorbid personality and nonpsychotic psychiatric disorders are common interdisciplinary problems in JME management. Most practitioners pay attention only to the treatment of seizures caused by JME, and their patients, accordingly, do not receive adequate psychotherapeutic help.

Conclusion. Cognitive disorders are often associated with epilepsy, and are a result of a combination of factors. According to our study, in the presence of statistically significant differences in short-term memory and mental performance in patients with JME, compared to healthy young adults, the main indicators of cognitive function in patients with JME generally correspond to the norm. Our findings highlight the etiological heterogeneity of cognitive disorders in JME and the importance of early screening for them.

Keywords: juvenile myoclonic epilepsy (JME), individual neuropsychological characteristics, cognitive functions, anxiety, depression. 


\section{Introduction}

JME was first described as a syndrome by Janz and Christian in 1957 (Janz, 1989).

Now JME is one of the most widespread forms of genetically determined generalized epilepsy (Avakyan, 2017), which is accompanied by the classical Herpin-Janz triad of symptoms: frequent myoclonic jerks, mostly in the upper limbs; possible generalized tonic-clonic seizures; and, less commonly, absence seizures (O'Muircheartaigh et al., 2012). The peak of disease onset is between ages 14 and 16, with a range from 8 to 26 years (Commission on Classification and Terminology of the International League Against Epilepsy [ILAE], 1989). Cases have also been diagnosed at a later age.

The typical interictal EEG abnormality consists of a generalized 4- to 6-Hz spike, or polyspike, and slow-wave discharges lasting 1-20 seconds. Usually, 1-3 spikes precede each slow wave. When absence seizures are present, a 3-Hz spikeand-wave activity may be seen in addition to the polyspike-and-wave pattern. Occasionally, isolated fragments of generalized spikes can also be seen. The background activity of the EEG is normal in patients with JME.

The seizures are often preceded by stress and disturbance in the circadian rhythm of sleep, with a predominance of seizures occurring shortly after awakening (83\% of patients). Also, a frequent cause of these seizures is sleep deprivation (77\%) (Wandschneider et al., 2012). A smaller proportion of patients report that seizures may be associated with "thoughts and concentration" (23\%) or hand activities (20\%) (Krauss, 2011; da Silva Sousa, 2005).

In our previous review of the literature about mental illness in JME patients (Moskaleva et al., 2017), we noted that, despite the fact that they recognize the factors «which cause more frequent seizures and worsening of the general condition, many patients cannot cope with their emotions singly; they note a decrease in stress resistance and therefore complain about the difficulties of falling asleep, resulting in an undesirable lack of sleep». The reason for such disorders may often be described as JME-concomitant nonpsychotic psychiatric disorders. They include various types of anxiety and mood disorders such as: generalized anxiety disorders, phobias, depression, dysthymia, and psychosomatic disorders (de Araújo Filho, 2009, Martínez-Domínguez, 2013; Somayajula, 2015).

Epilepsy is a socially significant disease.

B.V. Zeigarnik et al. have demonstrated how an alteration in physiological parameters can influence the course of mental processes in patients with epilepsy (Zeigarnik \& Bratus, 1980). People with epilepsy, especially children, feel themselves different from others (this is interesting especially in the context of JME study), and therefore look for a way to compensate for their condition (Zeigarnik, 1986). Consequently they take one of two characteristic approaches. In the first, the patient concentrates on an accurate, even pedantic understanding of the disease, and establishes a certain habitual, active attitude toward the world around them, a certain social position, i.e., makes JME a character trait. When the patient has preserved cognitive function, this approach even helps him or her in socialization. The second approach is an unsuccessful attempt at compensation, which leads to the formation of agoraphobia and depression. 
And in 2017 ILAE experts developed a new epilepsy classification which showed their serious concern over the underestimation of the comorbid conditions' effects on the JME patient's life. Despite the possibility of complete relief from seizures, JME and other epileptic diseases (such as benign epilepsy with centrotemporal spikes and children's absence epilepsy) may be associated with transient or long-term effects on the patient's cognitive domain (Avakyan, 2017).

There is also significant evidence that individuals with JME show subtle anomalies in brain structure, hence in cognition. For this reason, they have poor long-term social outcomes after 25 years, including social isolation and underemployment (Martínez-Domínguez et al., 2013; Somayajula et al., 2015).

The frontal lobes, especially the prefrontal cortex, play an important role in cognitive disorders (Wandschneider et al., 2012). Dysfunction in these areas results in deficits of executive functions (concept formation, abstract reasoning, planning, selfregulation of behavior, control of impulsivity, and emotions), the functions which manage cognitive and behavioral responses and strategies for the achievement of immediate or future goals (Lin et al., 2014; Kim et al., 2007).

According to our previous review of the scientific literature about cognitive impairment in patients with JME (Shilkina et al., 2017), four theories the causes of cognitive disorders in JME are currently being advanced:

1. The impact of epileptiform discharges and disease-related characteristics (Lee, J.M. et al., 2008; Motamedi et al., 2014; Holmes \& Lenck-Santini, 2006; Carvalho et al., 2016);

2. Adverse side effects (ASEs) of antiepileptic drugs (AEDs) (Thomas et al., 2014; Valente et al., 2016; Hamed, 2009);

3. A genetic predisposition theory (Iqbal et al., 2009; Wandschneider et al., 2010; Chachua et al., 2014; Noebels et al., 2012);

4. Cerebrocortical microdysgenesis (Woermann et al., 1999; Tae et al., 2008; Kim et al., 2015).

The first three reasons are endogenous, i.e., directly related to the disease itself. And ASEs caused by receiving AEDs are also exogenous, and, accordingly, manageable.

Of course, all AEDs have potential ASEs. However, it has been clinically noted that with an adequately chosen regimen, individually selected dosage, and timely correction of antiepileptic therapy depending on the concentration level of the drug in the blood, the cognitive sphere of JME patients remains quite protected.

The combination of cognitive impairments and personality traits in JME patients (unsteadiness, lack of discipline, hedonism, indifference to their disease) significantly complicates their treatment; for example, they forget to attend control visits, to take their medication regularly, etc.

Study of the internal picture JME patients have of their disease has shown they have a tendency to underestimate mental disorders (Zeigarnik, 1986).

Therefore it is very important to avoid cognitive impairments, and to maximally control the mental health of JME patients for the most effective management of the disease. 


\section{Method}

The goal of our research was to assess the state of cognitive function in young adult patients with JME, with the exclusion of the ASEs of AEDs, and to analyze the level of personality and situational anxiety, neuroticism, and depression in young adult patients with JME.

The study was conducted within the framework of a complex of studies on the topic "Clinical and genetic characteristics of juvenile myoclonic epilepsy," registration number AAAA-A16-116100710066-3 dated 07.10.2016, based at the Neurological Center of Epileptology, Neurogenetics and Brain Research at the University Clinic. The study was approved by the local ethics committee of Prof. V.F. VoynoYasenetsky Krasnoyarsk State Medical University.

We chose 26 adults with JME (Group One) and 26 healthy adults (Group Two) with unburdened neurological and psychiatric history. An exclusion criterion for Group One was the presence of ASEs associated with AED therapy.

Both groups were tested by the computer program NS-PsychoTest (Neurosoft Company, RF), which is aimed at studying and evaluating: 1) memory features (using Memory for Numbers); 2) attention (using Modified Schulte Tables as adapted by K.K. Platonov); 3) thinking (using Krepelin's Tables); 4) personal and situational anxiety (using Spielberger's State-Trait Anxiety Questionnaire as adapted by Y.L. Khanin); 5) depressiveness (using Beck's depression inventory (BDI)); 6) neuroticism (using Braithwaite's The Scale of Emotional Arousability as modified by A.A. Rukavishnikov and M.V. Sokolova); and 7) mental states (using Selfassessment of anxiety, frustration, aggressiveness and rigidity [AFAR]; Mantrova, 2010).

Our results produced a database, which we then processed statistically using the SPSS licensed software package, version 20.

All statistical analyses were carried out using licensed software package SPSS, version 20.0 (USA).We used the Student t-test and Fisher's test for characterization (quantity of normally distributed characteristics) and data comparison between the two groups. We calculated a 95\% confidence interval as the borders for expected deviation. Data for ordered samples with nonparametric distribution were presented with medians and quartiles (Me [pp. 25, 75]), and comparative statistics with the Mann-Whitney test.

\section{Results}

The average age of the JME patients in the study varied between 14 and 44 years of age, averaging $26.42 \pm 8.7$ years, with a median of 25 years (19:34). The age in Group Two varied between 19 and 36 years old, with an average age of $23.5 \pm 3.6$ years and a median of 22.5 years $(22: 24.5), \mathrm{p}=0.121$.

According to the WHO classification, people between 25 and 44 years old, are considered young; in other words, the age of our study participants is within this framework and corresponds to the stated topic.

The outcome of the testing by each method is presented below: 


\section{Braithwaite's Scale of Emotional Arousability as modified \\ by A.A. Rukavishnikov and M.V. Sokolova (See Table 1)}

While assessing emotional arousability, we took into account the totality of the following components: general emotionality, anger, timidity, and lack of control over emotions (Braithwaite, 1987).

The average score in Group One was: $36.64 \pm 10.39$ (27:44) among males, which corresponded to the fourth sthene (a tendency to low emotional excitability); and 45.0 \pm 10.62 (38:55) among females, which corresponded to the fifth or sixth sthene (average emotional excitability).

The average score in Group Two was 33.67 \pm 9.31 (25.75:41.75) for males, which corresponded to the third sthene (low emotional excitability); for females it was $39.5 \pm 5.99$ (35.25:44), which corresponded to the fourth sthene (a tendency to low emotional excitability) ( $\mathrm{p}>0.05)$.

Table 1. The Braithwaite's method «The Scale of Emotional Arousability» in the modification of A.A. Rukavishnikov and M.V. Sokolova

\begin{tabular}{lccc}
\hline Gender & Group $\mathbf{1}\left(\mathbf{n}_{\mathbf{1}}=\mathbf{2 6}\right)$ & Group 2 $\left(\mathbf{n}_{\mathbf{2}}=\mathbf{2 6}\right)$ & $\mathbf{p}$ (Student t-test's criterion) \\
\hline Males & $36.64 \pm 10.39$ & $33.67 \pm 9.31$ & $\mathrm{p}=0.447$ \\
Females & $45.0 \pm 10.62$ & $39.5 \pm 5.99$ & $\mathrm{p}=0.100$ \\
Total & $41.46 \pm 11.14$ & $36.8 \pm 8.09$ & $\mathrm{p}=0.091$ \\
\hline
\end{tabular}

$\mathrm{p}>0.05$

In Group One, especially among females, there was a tendency for an increased level of neuroticism as compared to the control group, but the intergroup differences did not reach statistical significance. Among the JME patients, six people (23\%) showed results within the eighth and tenth sthenes, i.e. the high emotional excitability, and three patients (11.5\%) were in the seventh sthene, i.e. showing a tendency to high emotional excitability. There were only two persons $(7.7 \%)$ with a tendency to high emotional excitability in the control group.

\section{Spielberger's State-Trait Anxiety Questionnaire as adapted by Y.L. Khanin}

(See Table 2)

The questionnaire was designed to assess the situational anxiety (SA) characterizing the patient's current mental state, and personal anxiety (PA), showing the predisposition of a person to this state.

Table 2. «Spielberger’s State-Trait Anxiety Questionnaire» in adaptation of Khanin Y.L.

\begin{tabular}{cccc}
\hline Scale & Group $\mathbf{1}\left(\mathbf{n}_{\mathbf{1}}=\mathbf{2 6}\right)$ & Group 2 $\left(\mathbf{n}_{\mathbf{2}}=\mathbf{2 6}\right)$ & $\mathbf{p}$ (Student t-test's criterion) \\
\hline SA & $37.92 \pm 8.11$ & $35.96 \pm 6.55$ & $\mathrm{p}=0.224$ \\
PA & $42.5 \pm 9.4$ & $38.46 \pm 8.03$ & $\mathrm{p}=0.078$ \\
\hline
\end{tabular}

$\mathrm{p}>0.05$ 
The middle score in Group One on the SA scale was 37.92 \pm 8.11 (34:41.5); on the PA, it was 42.5 \pm 9.4 (35.75:52.0). Therefore, the JME patients showed an average level of these parameters. Group Two showed similar middle values: $\mathrm{SA}=35.96 \pm 6.55$ (30.75:40); $\mathrm{PA}=38.46 \pm 8.03$ (31:44.25) $(\mathrm{p}>0.05)$.

Spielberger's questionnaire also provides an opportunity to compare the respondent's current state with his usual state of mind. SA arises as the reaction of a person to various, most often socio-psychological, stressors, when he or she expects a negative evaluation, or perceives an unfavorable attitude towards him or herself. This is a common anxiety among patients with epilepsy. PA gives an idea of the individual's exposure to these factors.

In six patients of Group One (23\%), there was a significant (more than 10 points) difference between the SA and PA in favor of PA. This result suggested a lower level of patient anxiety at a doctor's appointment (the patients «feel safer, more confident»), and a very high level of PA. This result requires clarification as to why, and as to how to conduct appropriate psycho-corrective measures.

\section{Self-assessment of anxiety, frustration, aggressiveness and rigidity (AFAR)}

(See Table 3)

The AFAR method measures four components: 1) anxiety (as a propensity to experience anxiety and a sense of failure);2) frustration (exposure to stress factors); 3) aggressiveness (inclination to aggressive reactions to life's difficulties); and 4) rigidity (inability to restructure one's own behavior).

According to the test results, the total score, interpreted as an indicator of the subject's general personal anxiety, was 111.42 \pm 14.41 (98.25:124.25) in Group One, i.e., the average level. In Group Two, the result was lower: 108.65 \pm 12.34 (102:119.25), although it also corresponded to the average level ( $\mathrm{p}>0.05)$.

It was also notable that nine patients in Group One (34.6\%) showed a high level of anxiety, which would require psychocorrectional work to reduce their level of PA. There was only one such case in Group Two (3.85\%).

Table 3. «Self-assessment of anxiety, frustration, aggressiveness and rigidity» (the method «AFAR»)

\begin{tabular}{|c|c|c|c|}
\hline Criterion & Group $1\left(n_{1}=26\right)$ & Group $2\left(n_{2}=26\right)$ & $\begin{array}{l}\mathbf{p} \text { (Student t-test's } \\
\text { criterion) }\end{array}$ \\
\hline $\begin{array}{l}\text { The indicator of the general } \\
\text { personal anxiety of the subject }\end{array}$ & $111.42 \pm 14.41$ & $108.65 \pm 12.34$ & $\mathrm{p}=0.460$ \\
\hline
\end{tabular}

$\mathrm{p}>0.05$

Beck's depression inventory (BDI) (See Table 4)

We used this method to assess the presence of depressive symptoms in the subjects' mental states during the period of testing. The BDI includes two subscales: cognitive-affective (CAS) and somatization (SS).

Group One's overall score for the BDI questionnaire was $8.96 \pm 10.09$ (1:11.75). This put it in the category (0-9 points) which is characterized by the absence of 
depressive symptoms. In Group Two, the result was significantly lower: $2.92 \pm 2.54$ (1:4.25), but this was also characteristic of the absence of depression $(\mathrm{p}=0.04)$.

Then we analyzed the data on the subscales. In Group One, the CAS score was $6.69 \pm 7.14(0: 10.75)$, in comparison with a norm ranging from 0 to 5; six people in the Group One (23\%) demonstrated a critical level of symptoms on CAS, and another six (also 23\%) showed moderately expressed symptoms of depression. The SS score was 2.27 $\pm 3.46(0: 3)$, in comparison with the norm, which ranges from 0 to 3. Consequently, there was a predominance of psychological symptoms over physiological symptoms.

In the control group, the CAS score was $1.77 \pm 1.48(1: 2.25)(\mathrm{p}=0.025)$, and the SS score was $1.15 \pm 1.52(0: 2)(\mathrm{p}=0.417)$. Such lack of significant difference in indicators corresponds to the norm.

The possible reason for the higher results in the patients' cognitive-affective sphere, along with the absence of somatic disorders, is an overestimation of the self-assessment of depression, a condition which requires the implementation of psychocorrectional assistance.

Table 4. Beck's depression inventory (BDI)

\begin{tabular}{cccc}
\hline Criterion & Group $\mathbf{1}\left(\mathbf{n}_{\mathbf{1}}=\mathbf{2 6}\right)$ & Group $\mathbf{2}\left(\mathbf{n}_{\mathbf{2}}=\mathbf{2 6}\right)$ & $\mathbf{p}$ (Mann-Whitney's criterion) \\
\hline Overall score & $8.96 \pm 10.09$ & $2.92 \pm 2.54$ & $\mathrm{p}=0.040^{*}$ \\
CAS & $6.69 \pm 7.14$ & $1.77 \pm 1.48$ & $\mathrm{p}=0.025^{\star}$ \\
SS & $2.27 \pm 3.46$ & $1.15 \pm 1.52$ & $\mathrm{p}=0.417$ \\
\hline
\end{tabular}

${ }^{*}=$ statistically significant intergroup differences.

\section{Memory for Numbers (See Table 5)}

We evaluated the subjects' short-term memory using this method.

The average number of correct answers in Group One was 7.42 \pm 1.77 (6:9), which corresponds to the normative result for young adults, which is seven correctly marked numbers or higher. Translated into our scoring system, the average score was $4 \pm 0.75$ (3:5) points, which corresponded to optimal efficiency of shortterm memory.

Table 5. The method «Memory for Numbers»

\begin{tabular}{lccc}
\hline \multicolumn{1}{c}{ Criterion } & Group 1 $\left(\mathbf{n}_{\mathbf{1}}=\mathbf{2 6}\right)$ & Group 2 $\left(\mathbf{n}_{\mathbf{2}}=\mathbf{2 6}\right)$ & $\mathbf{p}$ (Mann-Whitney's criterion) \\
\hline $\begin{array}{l}\text { The number } \\
\text { of correct answers }\end{array}$ & $7.42 \pm 1.77$ & $8.35 \pm 0.31$ & $\mathrm{p}=0.046^{\star}$ \\
The average score & $4 \pm 0.75$ & $4.38 \pm 0.7$ & $\mathrm{p}=0.061$ \\
\hline
\end{tabular}

*=statistically significant intergroup differences.

However, it should be noted that seven patients with JME (26.9\%) demonstrated a very high level of short-term memory, correctly indicating nine or ten num- 
bers, and scoring a maximal five points. At the same time, the seven other patients (26.9\%) had average results and decreased efficiency of mnestic processes (three points, i.e. five or six correctly marked numbers). No results of two points (one of four numbers), which correspond to low indicators of short-term memory, were recorded.

The average number of correct answers in Group Two was statistically significantly higher and amounted to $8.35 \pm 0.31(7: 10), \mathrm{p}=0.046$; the average score in the group 2 was $4.5 \pm 0.14$ (4:5) points, $\mathrm{p}=0.061$.

\section{Modified Schulte Tables as adapted by K.K. Platonov (See Table 6)}

We assessed the volume and stability of attention using this "Red-Black Table" technique. The differences in the middle level of attention in Groups One and Two were statistically insignificant $(\mathrm{p}>0.05)$.

Table 6. The method «Modified Schulte Tables» in adaptation of K.K. Platonov

\begin{tabular}{|c|c|c|c|}
\hline Criterion & Group $1\left(n_{1}=26\right)$ & Group $2\left(n_{2}=26\right)$ & p (Fisher's criterion) \\
\hline 1 (low level) & $7(26.9 \%)$ & $4(15.4 \%)$ & $\mathrm{p}=0.5303$ \\
\hline 2 (below the average) & 7 (26.9\%) & $6(23 \%)$ & $\mathrm{p}=0.5344$ \\
\hline 3 (average level) & $10(38.5 \%)$ & $10(38.5 \%)$ & $\mathrm{p}=0.5403$ \\
\hline 4 (above average) & $2(7.7 \%)$ & $4(15.4 \%)$ & $\mathrm{p}=0.3498$ \\
\hline 5 (high level) & $0(0 \%)$ & $2(7.7 \%)$ & $\mathrm{p}=0.5172$ \\
\hline
\end{tabular}

\section{Krepelin's Tables (See Table 7)}

Evaluation of thinking was carried out with the help of Krepelin's Tables; we assessed mental efficiency and fatigability, as well as stability and switching of attention. The average coefficient of mental efficiency is normally from 0.85 to 1.15. Among the patients with JME, it was $1.08 \pm 0.064$ (0.9:1.1); in the control group, it was $1.04 \pm 0.021(1.01: 1.14)$, which corresponds to the optimal level of operability, $\mathrm{p}=0.129$.

Table 7. The method «Krepelin's Tables»

\begin{tabular}{lccc}
\hline \multicolumn{1}{c}{ Criterion } & Group 1 ( $\left.\mathbf{n}_{\mathbf{1}}=\mathbf{2 6}\right)$ & Group 2 $\left(\mathbf{n}_{2}=\mathbf{2 6}\right)$ & $\begin{array}{c}\mathbf{p} \text { (Mann-Whitney's } \\
\text { criterion) }\end{array}$ \\
\hline $\begin{array}{l}\text { The average coefficient } \\
\text { of mental efficiency }\end{array}$ & $1.06 \pm 0.064$ & $1.06 \pm 0.021$ & $\mathrm{p}=0.129$ \\
$\begin{array}{l}\text { The occurrence's frequency } \\
\text { of operability's uneven } \\
\text { graphs }\end{array}$ & $14(53.85 \%)$ & $6(23 \%)$ & $\mathrm{p}=0.024^{*}$ \\
\hline
\end{tabular}

*=statistically significant intergroup differences 
In $7.7 \%$ of cases (two patients, native siblings with JME), a decreased coefficient of mental capacity of 0.8 and 0.81 was shown, which indicated the depletion of thinking and the presence of fatigability, and can be caused by patients'similar endophenotypes. A high coefficient was recorded in six patients (23\%).

It is also worth noting that, while showing optimal levels of mental activity, 14 patients (53.85\%) had uneven graphs (curve) of operability (Figure 1), which indicates emotional stress; this is typical for patients with JME due to their increased level of anxiety. By contrast, only six cases (23\%) of uneven graphs were noted among the individuals in the control group (Figure 2), $\mathrm{p}=0.024$.

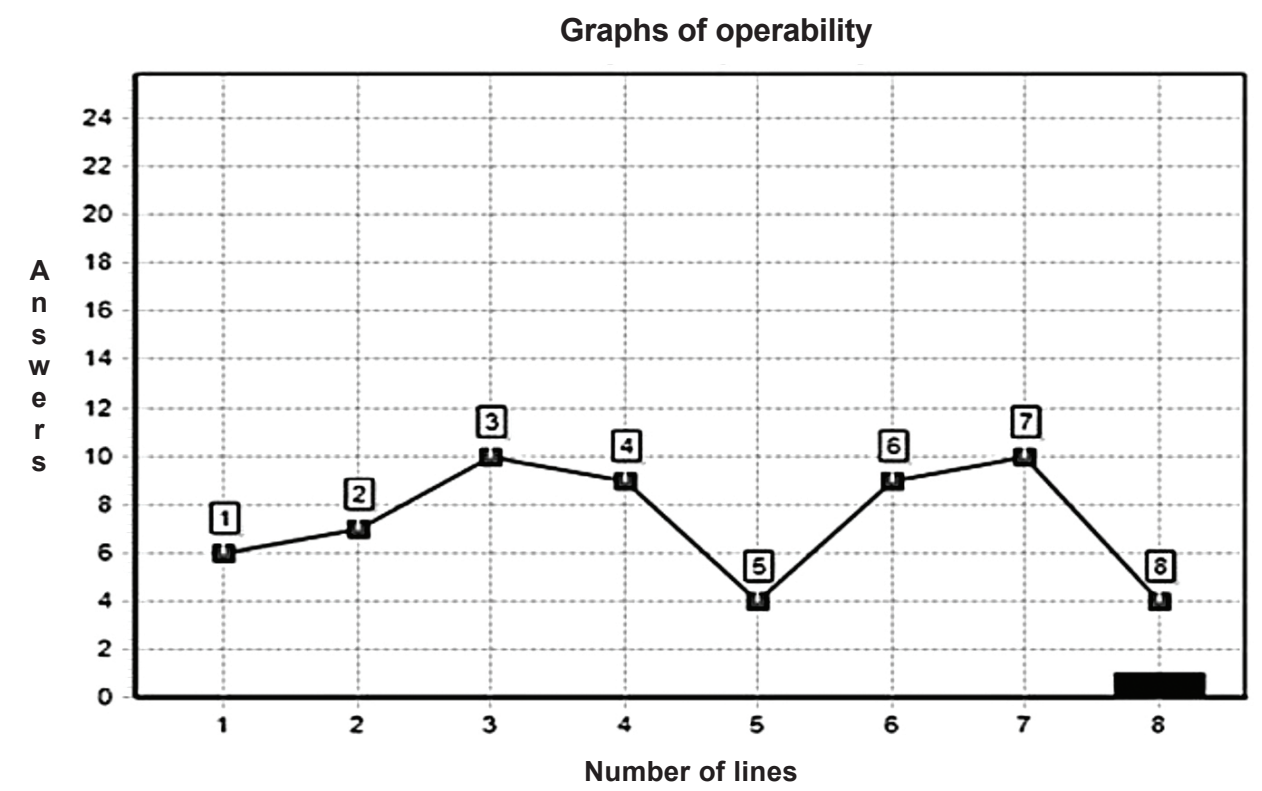

Figure 1. Uneven graphs of operability (patients - Group One)

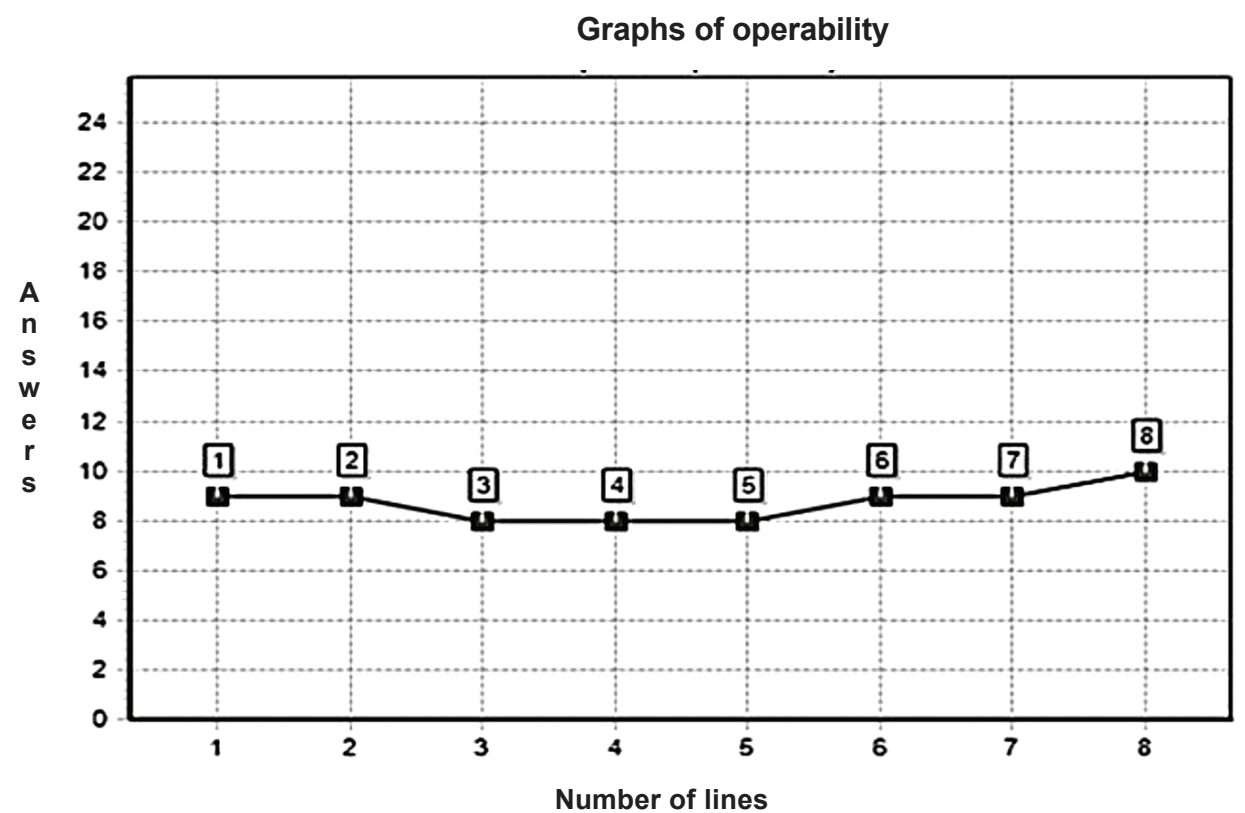

Figure 2. Even graphs of operability (controls - Group Two) 


\section{Discussion}

With balanced anti-epileptic therapy and the absence of AEDs' ASEs, the stigmatization of JME patients as patients with cognitive impairment does not be assumed to be true. Under modern conditions, it is necessary to revise the common attitude toward such patients in society. JME is not a reason for limiting these people from enrolling in higher education institutions, or from being hired for a job that requires a high intellectual level.

Our study showed that while there are statistically significant differences in short-term memory and mental performance in JME patients compared with healthy young adults, the main indicators of cognitive function among JME patients without AEDs' ASEs, in general, correspond to the norm.

At the same time, the incidence of depressive symptoms on the CAS in JME patients was statistically significantly higher than among people without epilepsy. The results allow us to take a new look at the management plan for patients with JME since the characteristics of their reactions generally were typical of other clinical forms of epilepsy.

Already in the 1930s, L.S. Vygotsky formulated the principle of the dynamic organization of psychological syndromes (Zinchenko \& Pervichko, 2012), and therefore their multifactor development (Zeigarnik \& Bratus, 1980). Following this theory, A.R. Luria and his followers formulated general methodological requirements for organizing the study of the psyche. Psychological syndromes are self-developing systems, dynamic structures possessing the qualities of self-regulation, self-organization, and self-determination. That was his main postulate. Subsequently, Zeigarnik's scientific school noted the multifactoriality of personality traits in patients with epilepsy. They concluded that the properties of the patient's character are formed in vivo, both in the norm and in pathology. (Zeigarnik, 1986).

Unfortunately, most practitioners only pay attention to the treatment of seizures in JME, while non-paroxysmal disorders, which are an integral part of this disease, remain insufficiently studied; thus patients do not receive adequate psychotherapeutic help. Behavioral, neuropsychological, and social problems often exceed the negative consequences of the seizures themselves. So dealing with the mental health problem in epilepsy is an important part of the strategy for patients' long-term care. Treatment of JME should aim to carry out disease-modifying psychotherapy or psycho-correction. Consequently, it requires an integrated approach and management of patients together with a psychotherapist.

\section{Conclusion}

Our findings highlight the etiological heterogeneity of cognitive disorders in JME (Shnayder, 2016).

The mental health problem in epilepsy is the important aspect of the strategy for patients' long-term care. The aim of the treatment of JME is to carry out a disease-modifying psychotherapy or psycho-correction. Consequently, it requires an integrated approach and management of patients together with a psychotherapist. 


\section{Acknowledgement}

This research and participation at the V International Luria Memorial Congress was supported by the Krasnoyarsk Regional State Autonomous Foundation Krasnoyarsk Region Science and Technology Support Fund.

Also the first author would like to thank the lecturers and coaches of the Fulbright Summer School on Academic Writing and Public Health (ENGLOHOLICS 2017) in the Siberian State Medical University, Tomsk, the Russian Federation.

\section{References}

Avakyan, G.N., Blinov, D.V., Lebedeva, A.V., Burd, S.G., \& Avakyan, G.G. (2017. ILAE classification of epilepsies: the 2017 revision and update. Epilepsy and Paroxysmal Conditions, 9(1), 6-25 [article in Russian] https://doi.org/10.17749/2077-8333.2017.9.1.006-025

Braithwaite, V.A. (1987). The Scale of Emotional Arousability: bridging the gap between the neuroticism construct and its measurement. Psychol. Med., 17(1), 217-25. https://doi. org/10.1017/S0033291700013106

Carvalho, K.C., Uchida, C.G., Guaranha, M.S., Guilhoto, L.M., Wolf, P., \& Yacubian, E.M. (2016). Cognitive performance in juvenile myoclonic epilepsy patients with specific endophenotypes. Seizure, 40, 33-41. https://doi.org/10.1016/j.seizure.2016.06.002

Chachua, T., Goletiani, C., Maglakelidze, G., Sidyelyeva, G., Daniel, M., \& Morris, E., et al. (2014). Sex-specific behavioral traits in the Brd2 mouse model of juvenile myoclonic epilepsy. Genes Brain Behav., 13(7), 702-12. https://doi.org/10.1111/gbb.12160

Da Silva Sousa, P., Lin, K., Garzon, E., Sakamoto, A., \& Yacubian, E.M. (2005). Self-perception of factors that precipitate or inhibit seizures in juvenile myoclonic epilepsy. Seizure, 14(5), 340-6. https://doi.org/10.1016/j.seizure.2005.04.007

De Araújo Filho, G.M., Lin, K., Lin, J., Peruchi, M.M., Caboclo, L.O., Guaranha, M.S., et al. (2009). Are personality traits of juvenile myoclonic epilepsy related to frontal lobe dysfunctions? A proton MRS study. Epilepsia, 50(5), 1201-9. https://doi.org/10.1111/j.1528-1167 .2009.02021.x

Hamed, S.A. (2009). The aspects and mechanisms of cognitive alterations in epilepsy: the role of antiepileptic medications. CNS Neurosci Ther., 15(2), 134-56. https://doi.org/10.1111/ j.1755-5949.2008.00062.x

Holmes, G.L. \& Lenck-Santini, P.P. (2006). Role of interictal epileptiform abnormalities in cognitive impairment. Epilepsy Behav., 8(3), 504-15. https://doi.org/10.1016/j.yebeh.2005.11.014

Iqbal, N., Caswell, H.L., Hare, D.J., Pilkington, O., Mercer, S., \& Duncan, S. (2009). Neuropsychological profiles of patients with juvenile myoclonic epilepsy and their siblings: a preliminary controlled experimental video-EEG case series. Epilepsy Behav., 14(3), 516-21. https:// doi.org/10.1016/j.yebeh.2008.12.025

Janz, D. (1989). Juvenile myoclonic epilepsy. Epilepsy with impulsive petit mal. Cleve Clin J Med, 56 Suppl Pt 1, S23-33; discussion S40-2.

Kim, J.H., Lee, J.K., Koh. S.B., Lee, S.A., Lee, J.M., Kim, S.I., \& Kang, J.K. (2007). Regional grey matter abnormalities in juvenile myoclonic epilepsy: a voxel-based morphometry study. Neuroimage, 37(4), 1132-7. https://doi.org/10.1016/j.neuroimage.2007.06.025

Kim, S.H., Lim, S.C., Kim, W., Kwon, O.H., Jeon, S., Lee, J.M., \& Shon, Y.M. (2015). Extrafrontal structural changes in juvenile myoclonic epilepsy: a topographic analysis of combined structural and microstructural brain imaging. Seizure, 30, 124-31. https://doi.org/10.1016/j. seizure.2015.06.009 
Krauss, G.L. (2011). Cognitive Activation of "Hyperexcitable Cortex" in JME: Can It Trigger Seizures? Epilepsy Curr., 11(6), 184-5. https://doi.org/10.5698/1535-7511-11.6.184

Lee, J.M., Kim, S.Y., Hwang, Y.H., Lee, H.W., Suh, C.K., \& Park, S.P. (2008). Longitudinal Assessment of Cognitive Function in Patients with Juvenile Myoclonic Epilepsy. Journal Korean Epilepsy Soc., 12(2), 85-91.

Lin, J.J., Dabbs, K., Riley, J.D., Jones, J.E, Jackson, D.C., Hsu, D.A., et al. (2014). Neurodevelopment in new-onset juvenile myoclonic epilepsy over the first 2 years. Ann Neurol., 76(5), 660-8. https://doi.org/10.1002/ana.24240

Mantrova, I.N. (2010). Metodicheskoye rukovodstvo po psikhofiziologicheskoy diagnostike (Methodical guidance on psycho-physiological diagnostics), 56, 58, 62, 78-79, 123-127. [Guidance in Russian]. Moscow.

Martínez-Domínguez, S., Labrada-Abella, J., Pedrós-Roselló, A., López-Gomáriz, E., \& TeníasBurillo, J.M. (2013). [Mental illness, personality traits and quality of life in epilepsy: control study of patients with juvenile myoclonic epilepsy and other epilepsies]. Rev. Neurol., 56(12), 608-14. [Article in Spanish].

Moskaleva, P., Shilkina, O., Artyukhov, I., Strotskaya, I., Dmitrenko, D., \& Shnayder, N. (2017). Nonpsychotic psychiatric disorders in juvenile myoclonic epilepsy. International Journal of Biomedicine, 7(2), 85-95. https://doi.org/10.21103/Article7(2)_RA1

Motamedi, M., Nasergivehch, S., Karamghadiri, N., \& Noroozian, M. (2014). Juvenile Myoclonic Epilepsy (JME): Neuropsychological Profile and Related Factors with Cognitive Dysfunction. Iran Journal Psychiatry, 9(1), 14-9.

Noebels, J.L., Avoli, M., Rogawski, M.A., Olsen, R.W., \& Delgado-Escueta, A.V. (2012). The next decade of research in the basic mechanisms of the epilepsies. In: Noebeles, J.L., Avoli, M., Rogawski, M.A., Olsen, R.W., \& Delgado-Escueta, A.V., editors. Jasper's basic mechanisms of the epilepsies. Oxford University Press, 3-11. https://doi.org/10.1093/ med/9780199746545.003.0001

O’Muircheartaigh, J., Vollmar, C., Barker, G. J., Kumari, V., Symms, M. R., \& Thompson, P., et al. (2012). Abnormal thalamocortical structural and functional connectivity in juvenile myoclonic epilepsy. Brain, 135 (Pt 12), 3635-44. https://doi.org/10.1093/brain/aws296

Proposal for revised classification of epilepsies and epileptic syndromes. Commission on Classification and Terminology of the International League Against Epilepsy. (1989). Epilepsia, 30(4), 389-99.

Shilkina, O., Artyukhov, I., Moskaleva, P., Strotskaya, I., \& Shnayder, N. (2017). Cognitive disorders in juvenile myoclonic epilepsy. International Journal of Biomedicine, 7(1), 9-14. https:// doi.org/10.21103/Article7(1)_RA1

Shnayder, N.A., Shilkina, O.S., Petrov, K.V., Chernykh, I.A., \& Diuzhakova, A.V. (2016). Clinical and genetic heterogenity of juvenile myoclonic epilepsy. Epilepsy and Paroxyzmal Conditions, 8(2), 20-36. [Article in Russian].

Somayajula, S., Vooturi, S., \& Jayalakshmi, S. (2015). Psychiatric disorders among 165 patients with juvenile myoclonic epilepsy in India and association with clinical and sociodemographic variables. Epilepsy Behav., 53, 37-42. https://doi.org/10.1016/j.yebeh.2015.09.024

Tae, W.S., Kim, S.H., Joo, E.Y., Han, S.J, Kim, I.Y., Kim, S.I., et al. (2008). Cortical thickness abnormality in juvenile myoclonic epilepsy. Journal Neurol., 255(4), 561-6. https://doi. org/10.1007/s00415-008-0745-6

Thomas, R.H., Walsh, J., Church, C., Sills, G.J., Marson, A.G., Baker, G.A., \& Rees, M.I. (2014). A comprehensive neuropsychological description of cognition in drug-refractory juvenile myoclonic epilepsy. Epilepsy Behav., 36, 124-9. https://doi.org/10.1016/j.yebeh.2014.04.027

Valente, K.D., Rzezak, P., Moschetta, S.P., de Vincentiis, S., Coan, A.C., \& Guerreiro, C.A. (2016). Delineating behavioral and cognitive phenotypes in juvenile myoclonic epilepsy: 
Are we missing the forest for the trees? Epilepsy Behav., 54, 95-9. https://doi.org/10.1016/j. yebeh.2015.10.022

Wandschneider, B., Thompson, P. J., Vollmar, C., \& Koepp, M. J. (2012). Frontal lobe function and structure in juvenile myoclonic epilepsy: a comprehensive review of neuropsychological and imaging data. Epilepsia, 53(12), 2091-8. https://doi.org/10.1111/epi.12003

Woermann, F.G., Free, S.L., Koepp, M.J., Sisodiya, S.M., \& Duncan, J.S. (1999). Abnormal cerebral structure in juvenile myoclonic epilepsy demonstrated with voxel-based analysis of MRI. Brain, 122 (Pt 11), 2101-8. https://doi.org/10.1093/brain/122.11.2101

Zeigarnik, B.V. \& Bratus, B.S. (1980). Ocherki po psikhologii anomalnogo razvitiya lichnosti (Essays on the psychology of abnormal personality development). Publishing house of the MSU. [Monograph in Russian].

Zeigarnik, B.V. (1986). (Pathopsychology). Publishing house of the MSU. [Book in Russian].

Zinchenko, Yu.P. \& Pervichko, E.I. (2012). Postneklassicheskaya metodologiya v klinicheskoy psikhologii: nauchnaya shkola L. S. Vygotskogo A. R. Luriya (Postnonclassical methodology in clinical psychology: LS Vygotsky's science school AR Luria). National Psychological Journal, (2), 32-45. [Article in Russian].

Original manuscript received September 30, 2017 Revised manuscript accepted March 15, 2018

First published online June 30, 2018 